\title{
Correction to: MicroRNA-206 Inhibited the Progression of Glioblastoma Through BCL-2
}

\author{
Wenjiong Hao ${ }^{1,2} \cdot$ Wei Luo ${ }^{3} \cdot$ Mangmang Bai $^{2} \cdot \operatorname{Jian} \mathrm{Li}^{2} \cdot$ Xiaobin Bai $^{1} \cdot \mathrm{Jie}_{\mathrm{Guo}}{ }^{2} \cdot$ Maode Wang $^{1}$ \\ Published online: 22 October 2020 \\ (C) Springer Science+Business Media, LLC, part of Springer Nature 2020
}

Correction to: Journal of Molecular Neuroscience (2016) 60:531-538.

https://doi.org/10.1007/s12031-016-0824-6

The original version of this article unfortunately contained a mistake in the AuthorGroup section. Jinsong Wu should be removed from the list of authors of this paper. He was included in the author group in error.

The authors apologize for this mistake.

Publisher's Note Springer Nature remains neutral with regard to jurisdictional claims in published maps and institutional affiliations.

The online version of the original article can be found at https://doi.org/ 10.1007/s12031-016-0824-6

Maode Wang

maodewang@163.com

1 Department of Neurosurgery, The First Affiliated Hospital, School of Medicine, Xi' an Jiaotong University, Xi'an 710061, People's

Republic of China

2 Department of Neurosurgery, Affiliated Hospital, Medical College of Yan'an University, Yan'an City, Shaanxi 716000, People's Republic of China

3 Department of Neurosurgery, The Affiliated Hospital of Shaanxi Traditional Chinese Medicine University, Xianyang 712000, People's Republic of China 